\title{
Women's Knowledge, Attitude and Practice on Cervical Cancer and Its Screening in Dhaka, Bangladesh
}

\author{
M.d Omar Qayum ${ }^{1 *}$, Mallick Masum Billah', Rehena Akhter², Meerjady \\ Sabrina Flora ${ }^{3}$
}

\begin{abstract}
Background: Cervical cancer is the fourth most common cancer among women in the world. Visual Inspection with Acetic Acid (VIA) is a common screening test for cervical cancer in Bangladesh. This study will assess the knowledge, attitude and practice towards cervical cancer and screening among women residing in Dhaka district. Methods: A cross-sectional survey was conducted among 956 women aged 30 years and above in Dhaka. The women's score on knowledge, attitude and practice were categorized as sufficient or insufficient. We calculated frequencies and used binary logistic regression to describe and assess the association between scores and socio-demographic characteristics of respondents. Results: Most (87\%) respondent knew about cervical cancer and 13\% knew that HPV is a risk factor for cervical cancer. Women who had sufficient knowledge were more likely to test VIA than those who had insufficient knowledge (39\%, OR: 2.5 ; CI: 1.6, 2.8). Most $(92 \%)$ would advise other women to have a VIA test. However, only $26 \%$ had a VIA test and $2 \%$ were vaccinated in private health care facilities for Human Papilloma Virus (HPV). Women who had sufficient attitude were equally likely to test VIA than those who had insufficient attitude. The VIA was underutilized because of low privacy during examination, unaware that VIA screened for cervical cancer, belief that they must pay for the test, and nurses performed examination. Conclusion: Women were knowledgeable about cervical cancer and likely to have a VIA test. However, the VIA test in underutilized and HPV vaccine coverage was low.
\end{abstract}

Keywords: Cervical cancer- screening,- VIA test- HPV- women- Bangladesh

Asian Pac J Cancer Prev, 22 (10), 3327-3335

\section{Introduction}

Cervical cancer is the most common cancer in developing countries (Goel et al., 2005). In Bangladesh, cervical cancer is the second presiding cause of cancer death of women aged 15-44 years. Age-standardized incidence rates of cervical cancer were 10.6 per 100000 Bangladeshi women in 2018. According to International Agency for Research on Cancer an estimated 604000 women were diagnosed with cervical cancer in 2020 with 342000 death. About 5,214 cervical cancer deaths occur annually in Bangladesh ("HPV INFORMATION CENTRE,"n.d).

Insufficient screening, high prevalence of risk factors, early marriage, sexual intercourse at an early age, high parity, low socio-economic condition is some of the reasons for the high burden of cancer in Bangladesh (n.d.). The majority of cervical cancer could be prevented if all women were participated in a screening program (Papri et al., 2015). According to WHO, Bangladesh screening guidelines recommend screening from 30 years of age with population screening coverage of women aged 30 to 49 years every three years.

With the assistance of Global Alliance for Vaccines and Immunizations (GAVI), Ministry of Health has introduced Human Papilloma Virus (HPV) vaccine in Bangladesh. According to WHO recommendations, girls are vaccinated with HPV vaccine between 9-13 years of age. In this regard Bangladesh piloted a school-based vaccination program that vaccinated 10 years old girls in primary schools in selected Upazilas. As part of the pilot, girls who cannot be vaccinated in school can get vaccinated through the routine EPI sites ("HPV vaccine introduced in Bangladesh,"n.d).

Smear cytology is the standard screening test for cervical cancer but it is challenging to implement in developing countries due to the unavailability of logistic pre-requisites and high-quality laboratories. In response to these challenges, more cost-effective alternative methods such as visual inspection are being tested for use in low-resource settings (Denny et al., 2006). Studies suggest that VIA is both sensitive and specific enough to reduce the incidence and mortality of cervical cancer in developing countries (Sankaranarayan et al., 2001). 
Early detection of cervical cancer by screening can prevent most cervical cancer cases. The Government of Bangladesh introduced screening services free of cost for all women of 30-60 years in all districts of Bangladesh ("Home-Bangladesh academy of Pathology (BAP),"n.d.). Awareness of the successful treatment magnitude of disease and possible warning signs of cervical cancer among the public is important for early identification and reduction of the burden of this disease.

With this objective, the present study was conducted to assess the level of knowledge, attitude and practice regarding cervical cancer and VIA screening among women.

\section{Materials and Methods}

\section{Methods and sampling}

The present study was a cross-sectional KAP survey among women aged 30 years and above. Among the area of Bangladesh where VIA screening program was ongoing, we selected Keraniganj Upazila and Tejgaon area of Dhaka district randomly. In these two areas, cervical cancer screening programme was ongoing. We considered Tejgaon area as urban area and Keraniganj as semi urban area. Using the Cochran's formula, we found a representative sample of 956 women for our study where 411 eligible women were from Tejgaon area and 545 women were from Keraniganj.

Our study population was recruited by going to every fifth household and identifying every woman 30 years of age and above in that household. If there was more than one eligible woman, one was randomly selected and interviewed after obtaining written informed consent. If there was no eligible woman in the fifth household, the team proceeded to the sixth household or the seventh or $\mathrm{n}^{\text {th }}$ until an eligible woman was recruited. After completion of the interview, the team repeated this sampling procedure. The study respected each respondent's freedom to participate and adhered to all research principles pertaining to privacy and confidentiality. Written informed consent was sought from all the participants.

\section{Exclusion criteria}

We excluded women below 30 years of age, those who were not permanently residing in Tejgaon and Keraniganj area, those who were not interested in participating, or did not give consent to be interviewed.

\section{Data collection tools and analysis}

A pre-tested questionnaire based on the study objectives was used to collect data. A face-to-face interview was taken at home after getting informed written consent from the respondents. Continuous variable like age, educational status, monthly expenditure, age at first marriage, number of alive children and parity were transformed into categorical variables for ease of analysis. The main outcomes of interest of this study were score of knowledge, attitude, and practice.

We calculated descriptive statistics like frequency and percentage of socio demographic characteristics of target population and women's score on knowledge, attitude, and practice of VIA test. We used a cut-off of greater or equal 11 to denote "sufficient score" on knowledge, greater or equal to 5 to denote "sufficient score" on attitude and greater or equal to 3 to define "sufficient score" on practice. To measure the association between women's socio demographic characteristics and undergone VIA test we used binary logistic regression. The association between respondent's score and socio demographic characteristics was also assessed by binary logistic regression. Stata 14.0 (Stata Corp. 2015. Stata Statistical Software: Release 14. College Station, TX: Stata Crop LP) was used to calculate frequencies and odds ratios.

\section{Results}

Socio demographic characteristics of the respondents regarding VIA screening

Table 1 shows that a total of 956 women were enrolled in our study. Among the study population highest proportion $(35 \%)$ of women belonged to the age group 31 to 35 years. More than half $(57 \%)$ of the population pertained to semi urban area and $26 \%$ of women had undergone through VIA test.

Table 2 implies that from the eligible respondents, women of 41-45 years old were more likely to test VIA than the youngest group (37\%, OR: $1.7 ; 95 \% \mathrm{CI}: 1.1,2.6)$. In semi urban area practicing of VIA test was lower than the urban area $(24 \%$, OR: $0.8 ; 95 \%$ CI: $0.6,1.0)$. There was a strong association between VIA screening and the level of education. Women who were from secondary educational level were more likely to go under VIA test than the illiterate women (35\%, OR: 1.8; 95\% CI: 0.8, 4.0) which was not statistically significant. Our study findings showed that testing VIA was likely to increase gradually with the increase of women's age at first marriage (43\%; OR: 2.9 , CI: $1.7,4.9)$ and with richest wealth quintile (31\%; OR: 1.9, CI: 1.2, 3.1)

Table 3 epidemiological studies showed that respondents had highest knowledge about cancer and cervical cancer and on the other hand they had lowest knowledge about Galactorrhea and sexually transmitted disease. Three top risk factors reported by respondents were early marriage, sexually transmitted disease, and unhygienic condition of cervix. Only 13\% knew HPV as a risk factor for cervical cancer. Half of the respondents had knowledge of tests for CA cervix detection. Among the study population $26 \%$ had ever tested VIA and only $2 \%$ had ever received HPV vaccine. We observed that proper privacy was not maintained in most cases during VIA test.

Table 4 showed that there was a significant association between socio-demographic characteristics and score of knowledge about cervical cancer. Women with higher knowledge were of younger age group, married, higher education, employee, higher income, non-Muslim, older age at first marriage and low parity. The knowledge on cervical cancer was likely to increase among women of secondary education level (70\%, OR: 5.02; CI: 2.19, 11.49) than the illiterate women and employed women (64\%, OR: 2.15 ; CI: $0.98,4.71)$ though it is statistically insignificant.

We found that sufficient score of attitudes towards 
Table 1. Socio Demographic Characteristics of Women, Keraniganj Upazila and Tejgaon area of Dhaka district, Bangladesh, 2017

\begin{tabular}{|c|c|c|}
\hline \multirow[t]{2}{*}{ Socio demographic characteristics } & \multicolumn{2}{|c|}{$\mathrm{N}=956$} \\
\hline & $\mathrm{n}$ & $\%$ \\
\hline \multicolumn{3}{|l|}{ Age (Years) } \\
\hline$\leq 35$ & 336 & 35 \\
\hline $36-40$ & 209 & 22 \\
\hline $41-45$ & 132 & 14 \\
\hline $46-50$ & 142 & 15 \\
\hline $51-55$ & 70 & 7 \\
\hline $56-60$ & 44 & 5 \\
\hline$>60$ & 23 & 2 \\
\hline $\operatorname{Mean}( \pm \mathrm{SD})$ & $41.23(9$. & \\
\hline Median (IQR) & $39(34-4$ & \\
\hline \multicolumn{3}{|l|}{ Marital status } \\
\hline Married & 845 & 88 \\
\hline Others & 111 & 12 \\
\hline \multicolumn{3}{|l|}{ Residence } \\
\hline Urban & 411 & 43 \\
\hline Semi Urban & 545 & 57 \\
\hline \multicolumn{3}{|l|}{ Educational status } \\
\hline Illiterate/only Signature & 230 & 24 \\
\hline Primary & 696 & 73 \\
\hline Secondary & 30 & 3 \\
\hline \multicolumn{3}{|l|}{ Occupation } \\
\hline Housewife & 928 & 97 \\
\hline Employee & 28 & 3 \\
\hline \multicolumn{3}{|l|}{ Monthly expenditure (Tk) } \\
\hline$\leq 15000$ & 269 & 28 \\
\hline $16,000-30,000$ & 565 & 59 \\
\hline $31,000-90,000$ & 122 & 13 \\
\hline Mean $( \pm \mathrm{SD})$ & 22099.4 & 6.4) \\
\hline Median (IQR) & $20000(15$ & $5500)$ \\
\hline \multicolumn{3}{|l|}{ Religion } \\
\hline Muslim & 931 & 97 \\
\hline Non-Muslim & 25 & 3 \\
\hline \multicolumn{3}{|l|}{ Age at first marriage (Years) } \\
\hline$\leq 15$ & 395 & 41 \\
\hline $16-20$ & 383 & 40 \\
\hline $21-25$ & 102 & 11 \\
\hline$\geq 26$ & 76 & 8 \\
\hline Mean $( \pm \mathrm{SD})$ & 17. & \\
\hline Median (IQR) & 16( & \\
\hline \multicolumn{3}{|l|}{ Number of alive children } \\
\hline 0 & 13 & 1 \\
\hline $1-2$ & 409 & 43 \\
\hline $3-5$ & 507 & 53 \\
\hline$>5$ & 25 & 3 \\
\hline \multicolumn{3}{|l|}{ Parity } \\
\hline $0-2$ & 281 & 30 \\
\hline $3-5$ & 594 & 62 \\
\hline
\end{tabular}

Table 1. Continued

\begin{tabular}{lcc}
\hline Socio demographic characteristics & $\mathrm{N}=956$ & \\
& $\mathrm{n}$ & $\%$ \\
\hline Parity & 77 & 8 \\
$>5$ & $3.5(3.1)$ & \\
Mean ( $\pm \mathrm{SD})$ & $3(2-4)$ & \\
Median (IQR) & & \\
Undergone VIA test & 249 & 26 \\
Yes & 707 & 74 \\
No & & \\
\hline
\end{tabular}

Table 2. Association between Women's Socio Demographic Characteristics and VIA Screening, Keraniganj Upazila and Tejgaon Area of Dhaka District, Bangladesh, 2017

\begin{tabular}{|c|c|c|c|c|}
\hline $\begin{array}{l}\text { Socio } \\
\text { demographic } \\
\text { characteristics }\end{array}$ & $\begin{array}{l}\text { Undergo } \\
\text { VIA test, } \\
\text { n (\%) }\end{array}$ & $\begin{array}{l}\text { Number of } \\
\text { respondents } \\
\text { (N) }\end{array}$ & OR $(95 \% \mathrm{CI})$ & $\begin{array}{c}\mathrm{P} \\
\text { value }\end{array}$ \\
\hline \multicolumn{5}{|l|}{ Age (Years) } \\
\hline$\leq 35$ & $86(26)$ & 336 & Ref & \\
\hline $36-40$ & $54(26)$ & 209 & $1.01(0.68-1.50)$ & 0.95 \\
\hline $41-45$ & $49(37)$ & 132 & $1.72(1.12-2.64)$ & 0.014 \\
\hline $46-50$ & $36(25)$ & 142 & $0.99(0.63-1.55)$ & 0.956 \\
\hline $51-55$ & $16(23)$ & 70 & $0.86(0.47-1.58)$ & 0.631 \\
\hline $56-60$ & $7(16)$ & 44 & $0.54(0.24-1.28)$ & 0.165 \\
\hline$>60$ & $1(4)$ & 23 & $0.13(0.02-1.00)$ & 0.049 \\
\hline \multicolumn{5}{|l|}{ Residence } \\
\hline Urban & $119(29)$ & 441 & Ref & \\
\hline Semi Urban & $130(24)$ & 545 & $0.77(0.58-1.03)$ & 0.076 \\
\hline \multicolumn{5}{|l|}{ Marital status } \\
\hline Married & $226(26.8)$ & 845 & Ref & \\
\hline Others & $23(21)$ & 111 & $0.72(0.44-1.16)$ & 0.176 \\
\hline \multicolumn{5}{|l|}{ Educational status } \\
\hline $\begin{array}{l}\text { Illiterate/only } \\
\text { Signature }\end{array}$ & $51(23)$ & 230 & Ref & \\
\hline Primary & $188(27)$ & 696 & $1.3(0.91-1.85)$ & 0.147 \\
\hline Secondary & $10(35)$ & 30 & $1.75(0.77-3.99)$ & 0.179 \\
\hline \multicolumn{5}{|l|}{ Occupation } \\
\hline Housewife & $239(26)$ & 928 & Ref & \\
\hline Employee & $10(36)$ & 28 & $1.6(0.73-3.52)$ & 0.241 \\
\hline \multicolumn{5}{|c|}{ Monthly expenditure (Tk) } \\
\hline$\leq 15,000$ & $52(20)$ & 269 & Ref & \\
\hline $16,000-30,000$ & $159(29)$ & 565 & $1.63(1.15-2.33)$ & 0.007 \\
\hline $31,000-90,000$ & $38(31)$ & 122 & $1.89(1.16-3.08)$ & 0.011 \\
\hline \multicolumn{5}{|l|}{ Religion } \\
\hline Muslim & $242(26)$ & 931 & Ref & \\
\hline Non-Muslim & $7(28)$ & 25 & $1.11(0.46-2.68)$ & 0.822 \\
\hline \multicolumn{5}{|c|}{ Age at first marriage (Years) } \\
\hline$\leq 15$ & $79(20)$ & 395 & Ref & \\
\hline $16-20$ & $111(29)$ & 383 & $1.63(1.17-2.27)$ & 0.004 \\
\hline $21-25$ & $27(27)$ & 102 & $1.44(0.87-2.38)$ & 0.156 \\
\hline$\geq 26$ & $32(43)$ & 76 & $2.91(1.73-4.88)$ & 0 \\
\hline \multicolumn{5}{|l|}{ Parity } \\
\hline $0-2$ & $67(24)$ & 281 & Ref & \\
\hline $3-5$ & $164(28)$ & 594 & $1.22(0.88-1.69)$ & 0.238 \\
\hline$>5$ & $17(22)$ & 77 & $0.9(0.49-1.66)$ & 0.746 \\
\hline
\end{tabular}

Asian Pacific Journal of Cancer Prevention, Vol 223329 
Table 3. Absolute and Relative (\%) Number of Women's Answer Claiming to have Knowledge, Attitude and Practice Regarding Cervical Cancer, Keraniganj Upazila and Tejgaon area of Dhaka district, Bangladesh, 2017

\begin{tabular}{|c|c|c|}
\hline \multirow[t]{2}{*}{ Characteristics } & \multicolumn{2}{|c|}{$\mathrm{N}=956$} \\
\hline & Yes, $n$ & $\%$ \\
\hline \multicolumn{3}{|l|}{ Knowledge on female's common disease } \\
\hline Cancer & 944 & 98 \\
\hline Cervical cancer & 836 & 87 \\
\hline Leucorrhea & 748 & 78 \\
\hline Dysmenorrhea & 401 & 42 \\
\hline Chronic infection in birth canal & 350 & 36 \\
\hline Breast cancer & 337 & 35 \\
\hline Sexually transmitted disease & 164 & 17 \\
\hline Galactorrhea & 33 & 4 \\
\hline \multicolumn{3}{|l|}{ Knowledge on risk factors on Ca Cervix } \\
\hline Early marriage & 527 & 55 \\
\hline Sexually transmitted disease & 401 & 42 \\
\hline Unhygienic condition of cervix & 313 & 33 \\
\hline Multiple sexual partners & 139 & 15 \\
\hline Conceive more than 5 times & 131 & 14 \\
\hline Human Papilloma Virus & 121 & 13 \\
\hline Long term use of contraceptives $>5$ years & 105 & 11 \\
\hline Habit of using tobacco & 46 & 9 \\
\hline Habit of using alcohol or substances & 64 & 7 \\
\hline \multicolumn{3}{|l|}{ Knowledge on prevention of Ca cervix } \\
\hline Early marriage & 591 & 62 \\
\hline Prevention of chronic infection & 238 & 25 \\
\hline HP vaccine use & 213 & 22 \\
\hline Avoid of multiple sexual partners & 184 & 19 \\
\hline Continuous use of condom & 133 & 14 \\
\hline \multicolumn{3}{|l|}{ Knowledge on symptoms of CA cervix } \\
\hline Heaviness in lower abdomen & 290 & 30 \\
\hline Foul smelling vaginal discharge & 238 & 25 \\
\hline Weight loss & 228 & 24 \\
\hline Bleeding in between periods & 216 & 23 \\
\hline Abdominal Pain after intercourse & 203 & 22 \\
\hline Bleeding after intercourse & 151 & 16 \\
\hline Vaginal bleeding after menopause & 90 & 9 \\
\hline \multicolumn{3}{|l|}{ Knowledge on test and treatments } \\
\hline Knowledge of treatment of Ca cervix & 618 & 65 \\
\hline Knowledge of tests for Ca cervix detection & 481 & 50 \\
\hline Cervical cancer vaccine & 358 & 37 \\
\hline \multicolumn{3}{|l|}{ Attitude regarding Ca cervix and screening } \\
\hline Will you advice another women to do a VIA test & 883 & 92 \\
\hline Do you ever recommend a VIA test for all women & 870 & 91 \\
\hline Willingness of nearest female neighbors to get VIA test & 597 & 62 \\
\hline Willing to undergo a VIA test in future & 563 & 59 \\
\hline After knowing risk, will you plan to do VIA test & 326 & 34 \\
\hline Do you think you have any risk for cervical cancer & 314 & 33 \\
\hline \multicolumn{3}{|l|}{ Practice regarding Ca cervix and screening } \\
\hline Did you ever receive HPV vaccine? & 18 & 2 \\
\hline $\begin{array}{l}\text { Have you participated in an awareness program } \\
\text { regarding Ca cervix and VIA test? }\end{array}$ & 59 & 6 \\
\hline Have you ever had a VIA test? & 249 & 26 \\
\hline Do you use napkin or clean cloth during menstruation? & 632 & 66 \\
\hline Did you seek medical teatment for female disease? & 778 & 81 \\
\hline
\end{tabular}

3330 Asian Pacific Journal of Cancer Prevention, Vol 22
VIA screening was likely to increase in employed and locals of semi urban area. Married women showed three times higher attitude towards VIA test than divorced, widowed or separated women $(18 \%$, OR: 0.3 ; CI: 0.2 , $0.5)$. The likelihood of showing attitude towards VIA test increasesd as the age at first marriage increasesd (49\%, OR: 1.9; CI: 1.1, 3.1).

In regards of practice, Table 4 showed that the women of 41-45 years old scored 1.8 times higher than the women of $\leq 35$ years old $(29 \%$, OR:1.8; CL: $1.1,2.8)$. The women who lived in semi urban area scored better than the women who lived in urban area $(20 \%$, OR: 1.3 ; CI: $0.9,1.3)$. Employed women were more likely to obtain a sufficient score than the housewife $(21 \%$, OR: 1.2 ; CI: $0.5,3.0)$ though it is not statistically significant.

One of the main concerns of our study was to find out the influencing characteristics of VIA screening. Our study findings showed a significant relationship between sufficient score of knowledge and going under VIA screening. Women who had sufficient knowledge were more likely to test VIA than who had insufficient knowledge (39\%, OR: 2.5; CI: 1.6, 2.8) (Table 5).

The main source of information regarding cervical cancer of the eligible women was friends and relatives (76\%) and followed by television (50\%). Regarding cervical cancer screening tests, most of them were informed by their friends and relatives or close acquaintances $(60 \%)$, followed by doctors $(50 \%)$ (Table 6).

\section{Discussion}

Early detection is essential to prevent cervical cancer. In Bangladesh, visual inspection with the acetic acid test is commonly used to detect cancer and helps in preventing deaths due to cervical cancer. Despite its effectiveness as a method of early detection and controlling cervical cancer incidence, our study showed significant underutilization of VIA screening test. According to Health Bulletin 2019, only $7.5 \%$ women aged 30 to 49 years in Bangladesh age group had gone under cervical screening test in their lifetime where our study showed that among 956 women, $26 \%$ of the participants in Dhaka District ever performed the VIA test. This increased difference is due to an ongoing cervical cancer prevention program in Dhaka District where we conducted this study. Another study in Bangladesh showed that only 300,000 women gone through VIA screening and a low coverage rate was observed during the cervical cancer screening program (Basu et al., 2010). In most studies, socio demographic factors of the participants such as age, income, and age at first marriage showed a positive association with the VIA test. The most represented age group of our study population was $\leq 35$ years which similar the study held in Cameroon (Agarwal et al., 2012). Our study findings showed that women of 41-45 years old were more likely to test VIA than the youngest group because cervical cancer tends to occur during midlife (Cervical Cancer Overview-NCCC,"n.d). This is consistent with a study conducted for developing countries (Dhamija et al., 1993). As expected, women living in urban areas in Bangladesh are more likely to have a VIA test than women living in 
Table 4. Association between Women's Socio-Demographic Characteristics and Sufficient Score of Knowledge, Attitude and Practice Regarding Cervical Cancer, Keraniganj Upazila and Tejgaon area of Dhaka district, Bangladesh, 2017

\begin{tabular}{|c|c|c|c|c|c|c|}
\hline \multirow{2}{*}{$\begin{array}{l}\text { Socio demographic } \\
\text { characteristics }\end{array}$} & \multicolumn{2}{|c|}{ Knowledge $(n=441)$} & \multicolumn{2}{|c|}{ Attitude $(\mathrm{n}=365)$} & \multicolumn{2}{|c|}{ Practice $(n=181)$} \\
\hline & $\begin{array}{c}\mathrm{N}(\%) \text { with score } \\
\geq 11 \text { (sufficient } \\
\text { knowledge of } \mathrm{CC})\end{array}$ & OR (L-U) & $\begin{array}{l}\mathrm{N}(\%) \text { with } \\
\text { score } \geq 5\end{array}$ & OR (L-U) & $\begin{array}{c}\mathrm{N}(\%) \\
\text { with score } \\
\geq 3\end{array}$ & OR (L-U) \\
\hline \multicolumn{7}{|l|}{ Age (Years) } \\
\hline$\leq 35$ & $173(52)$ & Ref & $159(48)$ & Ref & $63(19)$ & Ref \\
\hline $36-40$ & $104(50)$ & $0.93(0.66-1.32)$ & $89(43)$ & $0.93(0.66-1.32)$ & $41(20)$ & $0.83(0.58-1.17)$ \\
\hline $41-45$ & $63(48)$ & $0.86(0.57-1.29)$ & $50(34)$ & $0.86(0.57-1.29)$ & $38(29)$ & $0.68(0.45-1.02)$ \\
\hline $46-50$ & $55(39)$ & $0.6(0.4-0.89)$ & $41(29)$ & $0.6(0.4-0.89)$ & $20(14)$ & $0.45(0.3-0.69)$ \\
\hline $51-55$ & $24(34)$ & $0.49(0.29-0.84)$ & $16(30)$ & $0.49(0.29-0.84)$ & $13(19)$ & $0.33(0.18-0.6)$ \\
\hline $56-60$ & $13(30)$ & $0.4(0.2-0.78)$ & $8(18)$ & $0.4(0.2-0.78)$ & $5(11)$ & $0.25(0.11-0.55)$ \\
\hline$>60$ & $9(39)$ & $0.61(0.26-1.44)$ & $2(9)$ & $0.61(0.26-1.44)$ & $1(4)$ & $0.11(0.02-0.46)$ \\
\hline \multicolumn{7}{|l|}{ Marital status } \\
\hline Married & $402(48)$ & Ref & $345(41)$ & Ref & $163(19)$ & Ref \\
\hline Others & $39(35)$ & $0.6(0.4-0.9)$ & $20(18)$ & $0.6(0.4-0.9)$ & $18(16)$ & $0.32(0.19-0.53)$ \\
\hline \multicolumn{7}{|l|}{ Residence } \\
\hline Urban & $202(49)$ & Ref & $105(25)$ & Ref & $70(17)$ & Ref \\
\hline Semi urban & $239(44)$ & $0.81(0.62-1.04)$ & $260(47)$ & $0.81(0.62-1.04)$ & $111(20)$ & $2.66(2.01-3.51)$ \\
\hline \multicolumn{7}{|l|}{ Educational status } \\
\hline Illiterate/only Signature & $73(32)$ & Ref & $75(33)$ & Ref & $34(15)$ & Ref \\
\hline Primary & $347(50)$ & $2.14(1.56-2.93)$ & $280(40)$ & $2.14(1.56-2.93)$ & $141(20)$ & $1.39(1.02-1.91)$ \\
\hline Secondary & $21(70)$ & $5.02(2.19-11.49)$ & $10(33)$ & $5.02(2.19-11.49)$ & $6(20)$ & $1.03(0.46-2.32)$ \\
\hline \multicolumn{7}{|l|}{ Occupation } \\
\hline Housewife & $423(46)$ & Ref & $354(38)$ & Ref & $175(20)$ & Ref \\
\hline Employee & $18(64)$ & $2.15(0.98-4.71)$ & $11(39)$ & $2.15(0.98-4.71)$ & $6(21)$ & $1.05(0.49-2.27)$ \\
\hline \multicolumn{7}{|l|}{ Monthly expenditure (Tk) } \\
\hline$\leq 15,000$ & $107(40)$ & Ref & $124(46)$ & Ref & $42(16)$ & $\operatorname{Ref}()$ \\
\hline $16,000-30,000$ & $257(46)$ & $1.26(0.94-1.7)$ & $200(35)$ & $1.26(0.94-1.7)$ & $115(20)$ & $0.64(0.48-0.86)$ \\
\hline $31,000-90,000$ & $77(63)$ & $2.59(1.67-4.03)$ & $41(34)$ & $2.59(1.67-4.03)$ & $24(20)$ & $0.59(0.38-0.92)$ \\
\hline \multicolumn{7}{|l|}{ Religion } \\
\hline Muslim & $424(46)$ & Ref & $353(38)$ & Ref & $178(19)$ & Ref \\
\hline Non-Muslim & $17(68)$ & $2.54(1.09-5.95)$ & $12(48)$ & $2.54(1.09-5.95)$ & $3(12)$ & $1.51(0.68-3.35)$ \\
\hline \multicolumn{7}{|l|}{ Age at first marriage (Years) } \\
\hline$\leq 15$ & $157(40)$ & Ref & $133(34)$ & Ref & $54(14)$ & Ref \\
\hline $16-20$ & $193(50)$ & $1.54(1.16-2.05)$ & $148(39)$ & $1.54(1.16-2.05)$ & $87(23)$ & $1.24(0.93-1.66)$ \\
\hline $21-25$ & $55(54)$ & $1.77(1.14-2.75)$ & $47(46)$ & $1.77(1.14-2.75)$ & $22(22)$ & $1.68(1.08-2.62)$ \\
\hline$\geq 26$ & $36(47)$ & $1.36(0.83-2.23)$ & $37(49)$ & $1.36(0.83-2.23)$ & $18(24)$ & $1.87(1.14-3.07)$ \\
\hline \multicolumn{7}{|l|}{ Parity } \\
\hline $0-2$ & $148(54)$ & Ref & $109(39)$ & Ref & $48(17)$ & Ref \\
\hline $3-5$ & $268(45)$ & $0.74(0.56-0.98)$ & $231(40)$ & $0.74(0.56-0.98)$ & $125(21)$ & $1(0.75-1.34)$ \\
\hline$>5$ & $23(30)$ & $0.38(0.22-0.66)$ & $23(30)$ & $0.38(0.22-0.66)$ & $7(9)$ & $0.67(0.39-1.16)$ \\
\hline
\end{tabular}

Table 5. Association between Undergone VIA Screening and Score of Knowledge and Attitude, Keraniganj Upazila and Tejgaon area of Dhaka district, Bangladesh, 2017

\begin{tabular}{|c|c|c|c|c|c|}
\hline Scores & Undergo VIA-test, n (\%) & Crude OR & $95 \% \mathrm{CI}$ & Adjusted OR & $95 \% \mathrm{CI}$ \\
\hline \multicolumn{6}{|c|}{ Score of knowledge } \\
\hline Insufficient & $77(15)$ & Ref & & Ref & \\
\hline Sufficient & $172(39)$ & 3.64 & $2.67-4.95$ & 2.48 & $1.56-2.83$ \\
\hline \multicolumn{6}{|l|}{ Score of attitude } \\
\hline Insufficient & $145(24)$ & Ref & & & \\
\hline Sufficient & $104(28)$ & 1.22 & $0.91-1.64$ & & \\
\hline
\end{tabular}


Table 6. Source of Information Regarding Cervical Cancer, Keraniganj Upazila and Tejgaon area of Dhaka district, Bangladesh, 2017

\begin{tabular}{lcc}
\hline Source of information & $\mathrm{n}$ & $\%$ \\
\hline Source of information regarding cervical cancer & \\
Friends/ neighbors'/relatives & 634 & 76 \\
Television & 423 & 51 \\
Doctor & 398 & 48 \\
Health workers & 197 & 26 \\
Campaign & 93 & 11 \\
Nurse & 63 & 8 \\
Non-governmental organization & 43 & 5 \\
Internet & 28 & 4 \\
Radio & 24 & 3 \\
Source of information regarding cervical cancer screening \\
test & & \\
Friends/Relatives/close Acquaintances' & 290 & 60 \\
Doctor & 243 & 50 \\
Television & 168 & 35 \\
Health Workers & 97 & 20 \\
Any Campaign & 53 & 11 \\
Nurse & 38 & 8 \\
Internet & 19 & 4 \\
NGO & 11 & 2 \\
Radio & 11 & 2 \\
\hline
\end{tabular}

the semi urban area. Woldetsadik et al. also showed that women who were living in semi urban areas in country were less likely to be screened than women who were living in the urban area (Woldetsadik et al., 2020).

The results revealed that $87 \%$ of participants knew about cervical cancer which is consistent with the study done in Bangladesh (Rahman and Bhattacharjee, 2019; Islam et al., 2015). This result is also similar to a study conducted in Northern India where $92 \%$ of participants heard of cervical cancer (10) and in Congo it is $82 \%$ which is close to our study (Ali-Risasi et al., 2014). Touch et al. reported $74 \%$ of study women living in Kampong Speu, Cambodia, had ever heard about cervical cancer (Touch and Oh, 2018). Shrestha et al. said $66 \%$ had heard about cervical cancer (Shrestha et al., 2013). In our study, friends, neighbors, and relatives $(76 \%)$ were the primary information sources for cervical cancer and screening tests for the respondents. These results are congruent with those reported by Gupta et al., (2019). In a study done in Hosanna, Ethiopia, $10 \%$ of participants had VIA test for cervical cancer and $2 \%$ of the respondents had taken vaccine (Aweke et al.,2017). which is lower than reported by Gupta et al., (2019) where $5 \%$ of their participants had undertaken the HPV vaccination (Gupta et al.,2019) and $6 \%$ of them ever participated in any awareness program.

In our study, females knew about cervical cancer and recommended other women to get a VIA test but few women got a VIA test. In Bangladesh VIA screening is free and available in most medical college hospitals, Upazila health complex and maternal health and NGO clinics. Any women aged 30 years or above can request a
VIA test. Underutilization of VIA test may occur because women may be shy as the exam rooms are usually not private and they don't know anything about that VIA is a screening test for cervical cancer. The test is free, but most women think they have to pay for the test. Women have less confidence about the test because nurses instead of a doctor usually performs the VIA test. Women sometimes face social stigma if they test positive. In the author's experience, doctors prefer the Pap's smear over the VIA.

The major risk factors of cervical cancer are early marriage, sexually transmitted diseases, unhygienic conditions of cervix, and multiple sexual partners (Papri et al., 2015). Lack of awareness of these risk factors was one of the main causes of not having a VIA test. More than half of our study participants knew about early marriage as a risk factor for cervical cancer. This result is in agreement with a study in North West Ethiopia (Mengesha et al., 2020). Only a few of our participants (12\%) knew that HPV could be a risk factor for cervical cancer which is similar to a study in North West, Ethiopia (Mengesha et al.,2020). However, in studies in South African and Iraq in which, $49 \%$ and $37 \%$ of the respondents knew that HPV causes cervical cancer, respectively (Hoque and Hoque, 2009; Haseeb Hwaid, 2013). Women knew about cervical cancer but few of them knew that HPV vaccine could prevent cervical cancer. This could result in lower rate of vaccination to HPV.

Proper knowledge about cervical cancer and about its symptoms can reduce burden of this disease. If women don't know about the symptoms of cervical cancer, they will not seek treatment for those symptoms and thus cervical cancer may not be detected at the primary stage. Our study findings showed that respondents have less knowledge about the symptoms of cervical cancer. In our study $33 \%$ women thought that they might have risk of cervical cancer and respondents had lowest knowledge about sexually transmitted disease which should be increased to prevent cervical cancer caused by sexual transmissions. Among the study population $62 \%$ women knew that cervical cancer could be prevented by putting a stop to early marriage. More than one-fifth of the participants believed that HPV vaccine could prevent cervical cancer. It is similar in agreement with a study of Bangladesh (Islam et al., 2018). Half of our participants knew about the availability of screening tests for cervical cancer. It is consistent with this study of North West Ethiopia (Mengesha et al., 2020). But it is much lower than another study conducted in a tertiary hospital in India, where $85 \%$ of the women knew about screening tests for cervical cancer (Varadheswari et al., 2015). Nearly sixty-five percent of the participants knew that treatment could cure cervical cancer. It is much higher than the study conducted in North West Ethiopia, where only 28\% knew that cervical cancer is curable (Mengesha et al., 2020). This study showed that only $38 \%$ knew about the cervical cancer vaccine, which was very low. It is similar to this study, where $36 \%$ of the women knew about the preventive vaccine (Gupta et al., 2019).

Education has played a critical role in enhancing our participant's knowledge of cervical cancer. Cervical cancer knowledge is likely to increase gradually in women 
with secondary education than women with no education. A study in the Maldives showed knowledge improved with literacy level improvement (Basu et al., 2014). Dhamija et al. also brought out that literate women had better awareness about cervical cancer and related information (Dhamija et al., 1993). In another study in Ethiopia, literate women were more likely to be knowledgeable by 22.7 times than women who were illiterate (Kassa et al., 2019). The knowledge of testing VIA was more likely in employed women than housewives, but it was not statistically significant. Papri et al. showed that the knowledge of cervical cancer screening was significantly higher among the employed women. Emphasizing on higher education cervical can also be held back.

When women have greater attitude towards VIA screening then the trend of testing VIA will increase. The percentage of attitude among the majority of the respondents was high on parameters like willingness to do VIA tests in the future, advising anyone to do a VIA test. However, the attitude was low regarding other parameters. For instance, $33 \%$ believed in having the risk of cervical cancer, and even after knowing the risk, only $34 \%$ would plan to do a VIA test. In contrast, Narayan et al. reported that most of the respondents showed a positive attitude towards cervical cancer (Narayana et al., 2017). The VIA test attitude was 2.5 times higher in the respondents of semi-urban areas than the urban area. Married women showed three times higher attitude regarding the VIA test than divorced, widowed, or separated women. It seems that the likelihood of attitude towards VIA test increases as the age at first marriage increases. Education may play a role in preventing early age at first marriage.

With the help of UNFPA and Bangabandhu Sheikh Mujib Medical University (BSMMU), the Government of Bangladesh (GOV) started cervical cancer screening in all districts of Bangladesh. This screening program aims to test the women who are at risk though many of them may have no symptoms of the diseases. In developing countries though there are different screening program are ongoing, but these programs fail to meet their target screening of cervical cancer because of social and financial deficiency (Sankaranarayan et al., 2001). When the screening program will be well organized people will be more interested to participate in screening. Making the test more reliable to the women in root level can also increase the practice of testing VIA.

This study found that, although most participants knew about cervical cancer and screening tests, the percentage of VIA screening tests was low and practice of taking vaccine was very poor. The reason behind having low vaccine and less screening might be not being financially solvent, lack of logistics and social obstacles. Education, employment, residence, income plays a vital role in increasing knowledge, attitude, and the practice of cervical cancer screening test. This study reveals a significant relationship between a sufficient score of experience and undergoing a VIA test. Women who have sufficient knowledge are more likely to test VIA than those who have insufficient knowledge.

In conclusion, this study found that, although most participants knew about cervical cancer and screening tests, the percentage of VIA screening tests is low and practice of taking vaccine is very poor. Education, employment, residence, income plays a vital role in increasing knowledge, attitude, and the practice of cervical cancer screening test. This study reveals a significant relationship between a sufficient score of experience and undergoing a VIA test. Women who have sufficient knowledge are more likely to test VIA than those who have insufficient knowledge.

\section{Limitations}

This study had several limitations. Study participants were reluctant to answer sensitive questions which may bias results of associations. We recruited study subjects from two communities and are not representative of the country. Our study recruited women 30 years and above, thus our results cannot be interpreted for younger women. Study population did not include women from remote areas because of difficult terrain and lack of security for data collectors. Thus, conclusions may not represent all women in the communities we conduct this study. We did not conduct focus group discussions which would obtain more details on the knowledge, attitude and beliefs regarding cervical cancer and VIA screening.

\section{Recommendations}

Women need to know that VIA is a screening for cervical cancer and it is free to increase utilization of VIA. Attitude women are more confident when doctors perform the test rather than nurse. So if doctors can be rostered or counsel patient about testing procedure with privacy and confidentiality testing VIA would increase simultaneously. Expansion of awareness program regarding cervical cancer and giving more effort in changing attitude can influence the practice of having vaccine and undergoing VIA screening positively.

\section{Author Contribution Statement}

Md. Omar Qayum: conception, protocol writing, field activities and data collection, monitoring, supervision, analysis, manuscript writing and review, Mallick Masum Billah: analysis and manuscript review, Rehena Akhter: manuscript review, Meerjady Sabrina Flora: protocol writing, analysis and manuscript review.

\section{Acknowledgements}

We kindly thank TEPHINET, Alden Henderson (US CDC), Erin D Kennedy (US CDC), Denise Duran (US CDC), Mona Saraiya (US CDC), FETP,B fellows and graduates, all participants, Upazila Health Complex (Keraniganj and Tejgaon, Dhaka), Dr. Faisol Talukdar, FETP,B graduate :for survey assistance, Mehejabin Nurunnahar (Jahangirnagar University) for survey assistance and statistical advice.

\section{Funding}

Funding was provided by Training Programs in Epidemiology and Public Health Interventions Network (TEPHINET) and Centers for Disease Control and Asian Pacific Journal of Cancer Prevention, Vol $22 \mathbf{3 3 3 3}$ 
Prevention.

\section{Scientific approval}

This research study was approved by Institutional Review Board (IRB) of Institute of Epidemiology, Disease Control and Research, Mohakhali, Dhaka (IEDCR). Part of the study was used in Master's thesis in Applied Epidemiology course and this was a mini grant awards given by TEPHINET and US CDC.

\section{Ethical approval}

The ethical issue was handled by Institutional Review Board (IRB) of IEDCR's guidelines. In our study there were some sensitive questions and issues. We took written consent from every respondent and interviewed them with concealment and every data is reserved with confidentiality.

\section{Data availability}

Data is available upon reasonable request to the corresponding author.

\section{Data Registration}

This study was not registered in any dataset for clinical trials, guideline or meta-analysis.

\section{Conflict of interest}

None.

\section{References}

Agarwal P, Upadhyay R, Agarwal A (2012). Radiotherapy complications and their possible management in the head and neck region. Indian J Dent Res, 23, 843.

Ali-Risasi C, Mulumba P, Verdonck K, Vanden Broeck D, Praet M (2014). Knowledge, attitude and practice about cancer of the uterine cervix among women living in Kinshasa, the Democratic Republic of Congo. BMC Womens Health, 14, 30.

Aweke YH, Ayanto SY, Ersado TL (2017). Knowledge, attitude and practice for cervical cancer prevention and control among women of childbearing age in Hossana Town, Hadiya zone, Southern Ethiopia: Community-based cross-sectional study. PLoS One, 12, e0181415.

Basu P, Hassan S, Fileeshia F, et al (2014). Knowledge, attitude and practices of women in maldives related to the risk factors, prevention and early detection of cervical cancer. Asian Pac J Cancer Prev, 15, 6691-5.

Basu P, Nessa A, Majid M, Rahman JN, Ahmed T (2010). Evaluation of the National Cervical Cancer Screening Programme of Bangladesh and the formulation of quality assurance guidelines. J Fam Plann Reprod Health Care, 36, 131-4.

Cervical Cancer Overview - NCCC [WWW Document], n.d. . Nccc-online.org. URL https://www.nccc-online.org/ hpvcervical-cancer/cervical-cancer-overview/ (accessed 8.24.21).

Denny L, Quinn M, Sankaranarayanan R (2006). Chapter 8: Screening for cervical cancer in developing countries. Vaccine 24 Suppl 3, S3/71-7.

Dhamija S, Sehgal A, Luthra UK, Sehgal K (1993). Factors associated with awareness and knowledge of cervical cancer in a community: implication for health education programmes in developing countries. J R Soc Health, 113,
184-6.

Goel A, Gandhi G, Batra S, et al (2005). Visual inspection of the cervix with acetic acid for cervical intraepithelial lesions. Int J Gynaecol Obstet, 88, 25-30.

Gupta RK, Singh P, Langer B, et al (2019). Cervical cancer: a hospital based KAP study among women aged 18 years and above in Northern India. Int J Community Med Public Health, 6, 1628.

Haseeb Hwaid A (2013). Knowledge and awareness of Papillomavirus and cervical cancer among college students and health care workers women in diyala, Iraq. Am J Public Health Res, 1, 221-5.

Home - Bangladesh academy of Pathology Bangladesh academy of Pathology (BAP) [WWW Document], n.d. . Bapath.org. URL http://www.bapath.org (accessed 8.24.21).

Hoque E, Hoque M (2009). Knowledge of and attitude towards cervical cancer among female university students in South Africa. South. Afr J Epidemiol Infect, 24, 21-4.

HPV INFORMATION CENTRE [WWW Document], n.d.. Hpvcentre.net. URL http://www.hpvcentre.net (accessed 8.24.21).

Islam JY, Khatun F, Alam A, et al (2018). Knowledge of cervical cancer and HPV vaccine in Bangladeshi women: a population based, cross-sectional study. BMC Womens Health, 18, 15.

Islam RM, Bell RJ, Billah B, Hossain MB, Davis SR (2015). Lack of understanding of cervical cancer and screening is the leading barrier to screening uptake in women at midlife in Bangladesh: Population-based cross-sectional survey. Oncologist 20, 1386-1392.

Kassa, R.T., Gurmessa, T.O., Lemma, T.F., Abebe, W.S., (2019). Cervical cancer and screening method: Knowledge, attitude and practice among women living in Adama town. J Womens Health Care 8.

Mengesha, A., Messele, A., Beletew, B., (2020). Knowledge and attitude towards cervical cancer among reproductive age group women in Gondar town, North West Ethiopia. BMC Public Health 20, 209.

N.d. . Who.int. URL https://www.who.int/bangladesh/news/ detail/24-09-2017 (accessed 8.24.21).

Narayana G, Suchitra M, Sunanda G, et al (2017). Knowledge, attitude, and practice toward cervical cancer among women attending Obstetrics and Gynecology Department: A crosssectional, hospital-based survey in South India. Indian $J$ Cancer, 54, 481.

Papri FS, Khanam Z, Islam F, Hakim MM (20150. Knowledge and awareness about risk factors of cervical cancer, its screening and vaccination among the women attending Chittagong Medical College Hospital. Chattagram Maa-OShishu Hosp. Med Coll J, 14, 57-60.

Rahman F, Bhattacharjee A (2019). Awareness level of cervical cancer among rural women attending Manikgonj 250-bedded district hospital, Manikgonj. J Enam Med Coll, 9, 34-40.

Sankaranarayanan R, Budukh AM, Rajkumar R (2001). Effective screening programmes for cervical cancer in low- and middle-income developing countries. Bull World Health Organ, 79, 954-62.

Sankaranarayanan R, Esmy PO, Rajkumar R, et al (2007). Effect of visual screening on cervical cancer incidence and mortality in Tamil Nadu, India: a cluster-randomised trial. Lancet, 370, 398-406.

Saqer A, Ghazal S, Barqawi H, et al (2017). Knowledge and awareness about cervical cancer vaccine (HPV) among parents in Sharjah. Asian Pac J Cancer Prev, 18, 1237-41.

Shrestha J, Saha R, Tripathi N (2013). Knowledge, attitude and practice regarding cervical cancer screening amongst women visiting tertiary centre in Kathmandu, Nepal. Nepal J Med 
Sci, 2, 85-90.

Touch S, Oh J-K (2018). Knowledge, attitudes, and practices toward cervical cancer prevention among women in Kampong Speu Province, Cambodia. BMC Cancer, 18. https://doi.org/10.1186/s12885-018-4198-8.

Varadheswari T, Dandekar R, Sharanya T (2015). A Study on the Prevalence and KAP Regarding Cervical Cancer Among Women Attending a Tertiary Care Hospital in Perambalur.

Woldetsadik AB, Amhare AF, Bitew ST, et al (2020). Sociodemographic characteristics and associated factors influencing cervical cancer screening among women attending in St. Paul's Teaching and Referral Hospital, Ethiopia. BMC Womens. Health 20, 70.

World Health Organization (WHO). WHO guidelines for screening and treatment of precancerous lesions for cervical cancer prevention. Genève, Switzerland: World Health Organization; 2014.

\section{c) (i) (9)}

This work is licensed under a Creative Commons AttributionNon Commercial 4.0 International License. 